\title{
Quantitative Analysis of Nb in Steel Utilizing XRF-yield XAFS Edge Jump
}

\author{
Masayasu NAGOSHI, ${ }^{1) *}$ Tomohiro AOYAMA, ${ }^{2)}$ Yuji TANAKA, ${ }^{1)}$ Tomoharu ISHIDA, ${ }^{2)}$ Satoshi KINOSHIRO ${ }^{3)}$ \\ and Katsumi KOBAYASHI ${ }^{4)}$
}

1) Steel Research Laboratory, JFE Steel Corporation, 1, Kawasaki-cho, Chuo-ku, Chiba, 260-0835 Japan.

2) Steel Research Laboratory, JFE Steel Corporation, 1, Kokan-cho, Fukuyama, 721-8510 Japan.

3) Steel Research Laboratory, JFE Steel Corporation, 1-1, Minamiwatarida-cho, Kawasaki, 210-0085 Japan.

4) Photon Factory, KEK, 1 Oho, Tsukuba, Japan.

(Received on March 28, 2013; accepted on July 12, 2013)

\begin{abstract}
X-ray fluorescence (XRF) yield x-ray absorption fine structures (XAFS) have been investigated in terms of quantitative analysis for steel sheets containing 31-2100 ppm of $\mathrm{Nb}$. Nb concentrations in the samples were determined with high accuracy from the height of the K-edge jump. The detection limit was estimated down to the single digit ppm range. The combination of this technique with the conventional extended x-ray absorption fine structure (EXAFS) analysis for an identical XAFS spectrum provides both quantity and chemical state information of trace elements in the given volume of steel samples.
\end{abstract}

KEY WORDS: XAFS; XRF; EXAFS; synchrotron radiation; quantitative analysis; chemical state analysis; micro alloy; trace elements; $\mathrm{Nb}$; segregation.

\section{Introduction}

Micro-alloying elements added to the steel matrix dramatically change properties of steel products such as strength and corrosion resistance. For example, nanometer-sized precipitates, such as carbides formed by various elements, effectively improve the strength of steel. ${ }^{1)}$ It is therefore important to understand the roles these elements have on the properties of steel for designing micro-alloyed steel products of superior performance. The fundamental information about the micro-alloying elements are their quantity and chemical state, although size and distribution of precipitates are also important parameters regarding the strength of the steel if the elements form small precipitates. ${ }^{2}$

XAFS is a powerful tool for clarifying chemical states and local structures of specific elements in steel. ${ }^{3-6)} \mathrm{X}$-ray fluorescence (XRF) yield XAFS techniques have the advantage of high sensitivity to trace elements. This technique is especially valuable for elements substituting matrix atoms and forming atomic level clusters or nanometer-sized precipitates. These are difficult to detect by conventional high-resolution transmission microscopy (TEM). Another advantage of XAFS analysis is that chemical states are nondestructively investigated for rather large averaged volumes (typically up to several $\mathrm{mm}^{2}$ in area and tens of $\mu \mathrm{m}$ in depth) of samples.

Conventionally, quantities of added trace elements are determined by chemical analysis. When quantity and chemical state are studied by chemical analysis and XAFS, respectively, for micro-alloyed elements, one latent problem

* Corresponding author: E-mail: m-nagoshi@jfe-steel.co.jp DOI: http://dx.doi.org/10.2355/isijinternational.53.2197 is the inconsistency between their results caused by the difference in the measured volume for each technique. This is fatal especially for inhomogeneous or non-uniform samples. Compilation of the different information is required for identical volumes of such samples.

A study has reported the potential of XAFS as a quantitative analysis method for $\mathrm{Cl}$ and $\mathrm{Br}$ in environmental matters. ${ }^{7)}$ The concentration of $\mathrm{Cl}$ was successfully determined in the concentration range from single digit ppm to $1400 \mathrm{ppm}$. The authors pointed out the advantage of the simultaneous determination of quantity and chemical state for $\mathrm{Cl}$ and $\mathrm{Br}$. Their results clearly demonstrate the quantitative ability of the XRF-yield XAFS. However, there is no such report relating to research with metals. In this paper we have investigated the quantitative factor of the XRF-yield XAFS for trace elements in steel. The XAFS spectra have been recorded for small amounts of $\mathrm{Nb}$ added to steel and used for the quantitative and chemical state analysis.

\section{Experiment}

15 low-alloyed steel samples containing 31-2 100 ppm $\mathrm{Nb}$ were collected. The chemical composition of the base steels differed among samples. The $\mathrm{Nb}$ concentrations were determined by conventional chemical analysis. A sample containing $2100 \mathrm{ppm} \mathrm{Nb}$ was prepared as a reference for $\mathrm{Nb}$ which is substitutional in the bcc-Fe matrix by water quench from $1200^{\circ} \mathrm{C} . \mathrm{Nb}$ atoms in the other samples were partly precipitated due to different treatment. All samples were cut into small pieces and mirror-polished for XAFS measurement. The XAFS spectrum for commercial $\mathrm{NbC}$ powder was also measured in the transmission mode. The powder 
was mixed with $\mathrm{BN}$ and pelletized.

The XAFS experiment was carried out at beam line BL27B, Photon Factory (2.5 GeV, Tsukuba, Japan) with a two-crystal Si (111) monochromator. The Nb-K edge XAFS spectra were recorded in the X-ray fluorescence mode using a 7-element solid-state detector. The detector window (Region of Interest; ROI) was set to the $\mathrm{Nb}-\mathrm{K} \alpha$ emission peak. A $\mathrm{Zr}$ filter $(\mu \mathrm{t}=3)$ was set at the front of the detector. The beam size of the incident $\mathrm{x}$-ray was limited to $1 \mathrm{~mm}$ in height and $12 \mathrm{~mm}$ in width (16 $\mathrm{mm}$ for the sample with 31ppm $\mathrm{Nb}$ ) using a 4-dimension slit placed at the front of an ion chamber measuring the intensity of the incident $\mathrm{x}$-ray. The dwell time was set at $4 \mathrm{sec} /$ point and the spectra were measured by accumulation of from 1 to 3 cycles according to the $\mathrm{Nb}$ concentration. All samples were set in an identical position where the angles between sample surfaces and both incident $\mathrm{x}$-ray and detector were 45 degrees. The analysis of the XAFS spectra was performed with a commercial software package (Rex 2000, Rigaku Corp.).

The edge jump determined by the difference between $\mu_{0}$ $(\mathrm{h} v)$ and background $\mu_{\mathrm{B}}(\mathrm{h} v)$ corresponds to the net intensity of the $\mathrm{Nb}-\mathrm{K} \alpha$ emission peak exited by the $\mathrm{x}$-ray with photon energy $\mathrm{h} v$. Therefore, edge jump can be directly used to quantify the concentration of the target elements in the same manner as the net intensity in XRF analysis. Where $\mu_{0}$ is an $\mathrm{X}$-ray absorption curve for isolated atoms and is obtained by removing the EXAFS modulations caused by photoelectron interference from neighboring atoms.

The height of the Nb-K edge jump was evaluated as follows: 1) A smooth $\mu_{0}(\mathrm{~h} v)$ curve was drawn using a cubic spline method. 2) A background curve $\mu_{\mathrm{B}}(\mathrm{h} v)$ above the $\mathrm{Nb}-\mathrm{K}$ edge was estimated as that the difference between the $\mu_{\mathrm{B}}(\mathrm{h} v)$, which smoothly connects to the spectra below the edge region, and the $\mu_{0}(\mathrm{~h} v)$ obeys the Victoreen equation as a function of wave length (photon energy $h v$ ). ${ }^{8)}$ 3) The height of the edge was determined by the difference between the $\mu_{\mathrm{B}}(\mathrm{h} v)$ and $\mu_{0}(\mathrm{~h} v)$ at an identical photon energy region above the edge. In this study an average value between $19050 \mathrm{eV}$ and $19150 \mathrm{eV}$ was used. The background above the edge is estimated by an exsertion from the $\mu(\mathrm{h} v)$ curve below the edge to above the edge in the conventional method. However, this often fails for the XRF-yield mode XAFS spectra, due to the low intensity and abnormal shape of the background, and therefore Step 2) above is valuable.

\section{Results}

The Nb-K edge was clearly observed for all specimens using XRF-yield mode XAFS measurement. Figure 1(a) shows $\mathrm{Nb}-\mathrm{K}$ edge XAFS spectra for the samples containing $31,148,450$, and $2100 \mathrm{ppm} \mathrm{Nb}$. No $\mathrm{Nb}-\mathrm{K}$ edge structure was observed for a standard specimen including no $\mathrm{Nb}$ (JSS1000-1) under the same experimental conditions. The height of the edge jump changes with $\mathrm{Nb}$ concentration. The spectrum for the steel with 2100-ppm $\mathrm{Nb}$ shows typical EXAFS oscillations for solid solution elements in the bccFe matrix. The spectral shape for the steel with 450-ppm Nb is actually broader than this. This shows that the chemical state of $\mathrm{Nb}$ in this sample differs from the solid solution in the bcc matrix. This difference was caused by differences in heat treatment between the samples and is unrelated to $\mathrm{Nb}$
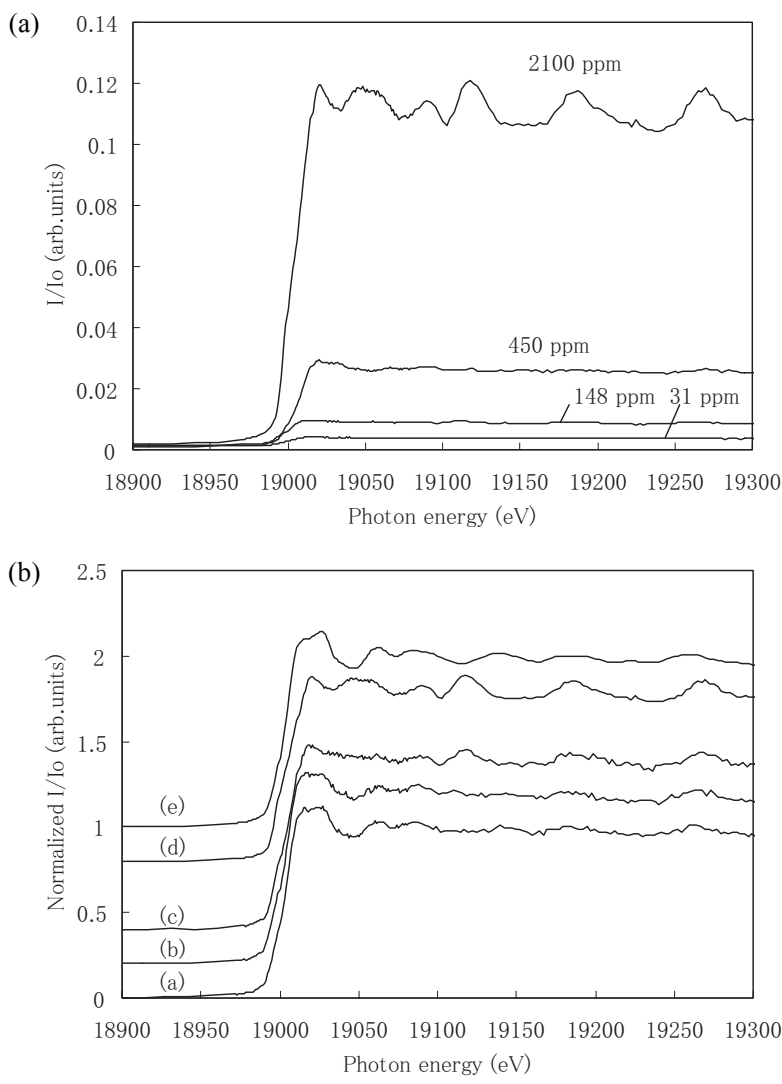

Fig. 1. (a) Nb-K edge XAFS spectra for the samples containing $\mathrm{Nb}$ of $31,110,500$, and $2100 \mathrm{ppm}$. I/Io scale is not normalized. (b) Normalized $\mathrm{Nb}-\mathrm{K}$ edge XAFS spectra for the samples containing $\mathrm{Nb}$ of around $150 \mathrm{ppm}$ (spectra $\mathrm{a}-\mathrm{c}$ ), $\mathrm{Nb}$ in the bcc-Fe matrix (spectrum d), and NbC (spectrum e).

concentration. The normalized XAFS spectra for the three samples containing approximately $150 \mathrm{ppm} \mathrm{Nb}$ are shown in Fig. 1(b) [spectra (a)-(c)]. The Nb-K XAFS spectra are different among these three samples. Spectrum (a) is similar to that for $\mathrm{NbC}$ [Spectrum (e)]. On the contrary, Spectrum (c) shows the characteristics of a spectrum for $\mathrm{Nb}$ atoms in the bcc-matrix [Spectrum (d)]. This shows that the fractions of precipitated $\mathrm{Nb}$ and dissolved $\mathrm{Nb}$ differ among samples although the $\mathrm{Nb}$ concentrations are in the same range.

Figure 2 shows the relationship between $\mathrm{Nb}$ concentration and $\mathrm{Nb}-\mathrm{K}$ edge jump evaluated by the method mentioned in the previous section. In Fig. 2(a), there exists good correlation between them in the wide $\mathrm{Nb}$ concentration range from 31 to $2100 \mathrm{ppm}$. The dashed line in the figure was obtained by least-square fit. The $\mathrm{R}^{2}$ value of the line nears 1 , which demonstrates that the $\mathrm{Nb}$ is quantified with high accuracy by $\mathrm{Nb}-\mathrm{K}$ edge jump throughout such a wide concentration range. The expanded plot in the $\mathrm{Nb}$ concentration range of around $150 \mathrm{ppm}$ is shown in Fig. 2(b). These samples belong to a series having almost the same chemical composition. A linear relationship is seen and a difference of less than $10 \mathrm{ppm}$ is easily distinguished. This result suggests that higher quantitativeness is achieved when the chemical composition of matrices are similar among samples.

The fractions of precipitated and dissolved $\mathrm{Nb}$ were evaluated from the identical XAFS spectra used for the quantitative analysis. In this study, the fraction of $\mathrm{Nb}$ in the 
(a)

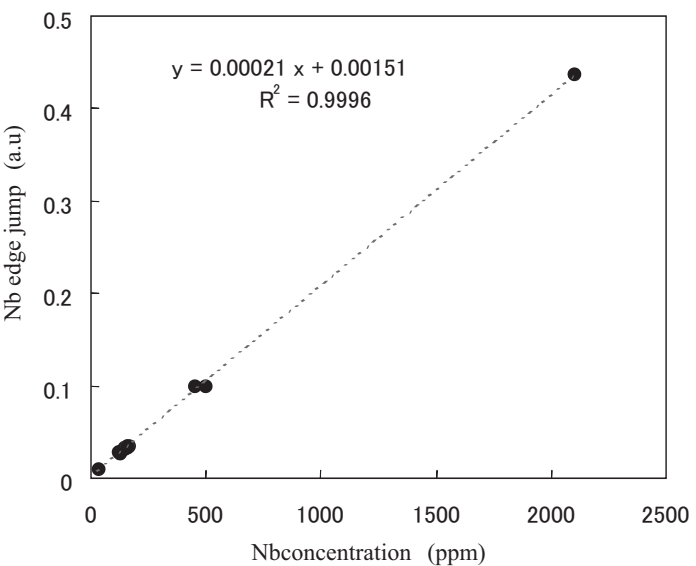

(b)

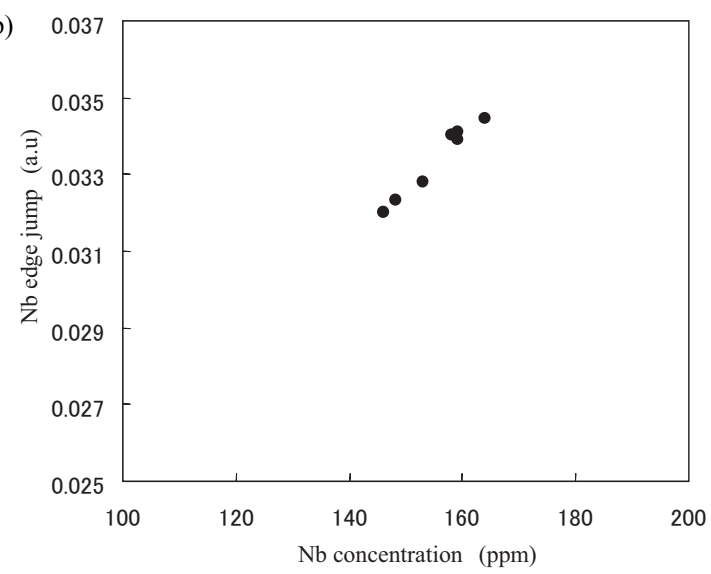

Fig. 2. Relationship between $\mathrm{Nb}-\mathrm{K}$ edge jump and $\mathrm{Nb}$ concentration determined by chemical analysis in a wide $\mathrm{Nb}$ concentration range (a) and in an $\mathrm{Nb}$ concentration of around 150 ppm (b). A line determined by a least squares fitting is shown with the equation and the $\mathrm{R}^{2}$ value in Fig. (a).

bcc-matrix (x) was determined using the EXAFS analysis technique. ${ }^{6}$ The average coordination number of $\mathrm{Fe}$ atoms around the dissolved $\mathrm{Nb}$ atoms was evaluated by a curve fitting for the inverse FT curves $\left(\mathrm{k}^{3}\right.$-weighted) of the $1^{\text {st }}$ and $2^{\text {nd }}$ nearest neighbors. The ratio of the $1^{\text {st }}$ and $2^{\text {nd }}$ nearest neighbors was fixed to $8 / 6$. A backscattering factor, a phase shift, and a Debye-Waller factor were derived from the analysis of the reference sample (2 100-ppm $\mathrm{Nb}$ ) quenched from $1200^{\circ} \mathrm{C}$ and fixed in the analysis of the other samples. The atomic fraction of $\mathrm{Nb}$ atoms in solution $(\mathrm{x})$ in the bcc matrix was estimated from the coordination number assuming that the coordination number for the reference sample was 1 . The fraction of precipitated $\mathrm{Nb}$ was determined as $1-\mathrm{x}$. The concentration of precipitated $\mathrm{Nb}$ can be quantified by multiplying the factor $(1-\mathrm{x})$ by the $\mathrm{Nb}$ concentration determined using the calibration curve (Fig. 2(a)).

Recently, a simple and accurate analytical method for determining solid solution content of micro-alloying elements has been developed using the electrolytic extraction method. ${ }^{9)}$ We compared our results with those of this chemical analysis for the 11 samples having $\mathrm{Nb}$ concentrations of around $150 \mathrm{ppm}$. The results are shown in Fig. 3. There is good correlation $\left(\mathrm{R}^{2}=0.912\right)$ between the two methods for precipitated $\mathrm{Nb}$ of $30-120 \mathrm{ppm}$ (corresponding to fractions of precipitated $\mathrm{Nb}$ between 22 and $84 \%$ ). There are some points not following the 45-degree curve in the figure, however, these inconsistencies were caused by the differences in

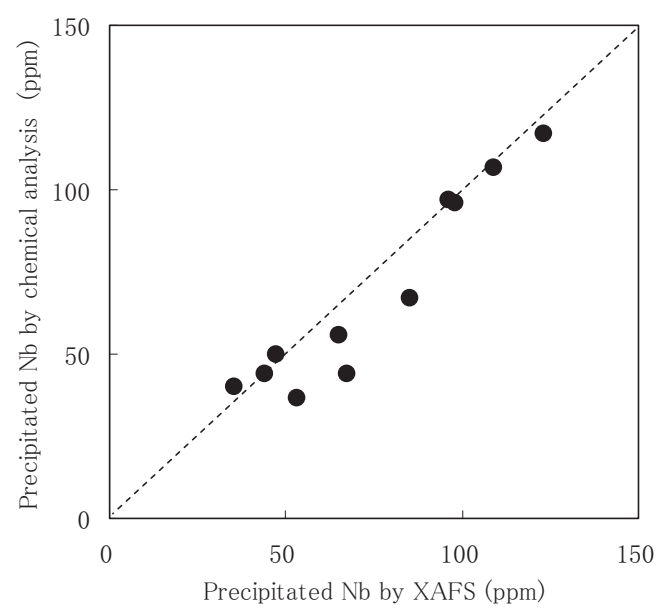

Fig. 3. Relationship between concentrations of precipitated $\mathrm{Nb}$ estimated by XAFS analysis in this study and chemical analysis on samples including $\mathrm{Nb}$ of around $150 \mathrm{ppm}$.

estimated fractions of precipitated (dissolved) $\mathrm{Nb}$, not in estimated $\mathrm{Nb}$ concentrations.

It should be emphasized that the method using XAFS is not destructive while chemical analysis is. However, we think that these two methods are complementary for inhomogeneous samples because chemical analysis provides overall average values while the XAFS provides analysis for selected local areas.

\section{Discussion}

The detection limit for $\mathrm{Nb}$ by our experimental setup was estimated from the XAFS spectrum for the 31-ppm Nb steel sample. The relationship between noise level $(3 \sigma)$ and the slope of the correlation curve (Fig. 2(a)) provided a detection limit of less than $3 \mathrm{ppm}$. This value is limited by the rather high noise smearing the edge jump of the spectra. Performance can be improved by increasing signal/noise $(\mathrm{S} / \mathrm{N})$ ratio making it possible to detect very weak edge jumps. In order to increase the $\mathrm{S} / \mathrm{N}$ ratio, combinations of brighter synchrotron radiation sources and higher through-put X-ray detectors are advantageous. We consider that the detection limit and quantitative limit of XAFS might be better than XRF spectroscopy using solid state detectors because the former method uses many data points directly corresponding to the net intensity of the x-ray emission from target elements. This is valuable especially when the XRF peak cannot be identified due to superimposition from other $\mathrm{x}$-ray emissions.

The method used in this study can be readily expanded to other metallic elements in steel or in other metallic matrices. An advantage of the method is that the quantity and chemical state of the target element are determined for identical sample volumes. In practice, samples are not always uniform or homogenous, due to segregation of elements during solidification and heat treatment, for example. Processing, such as welding and forming, may create areas where element concentrations and chemical states maybe altered from the original material. In such cases, chemical states and element concentrations should be evaluated at identical locations on each sample. The XAFS analysis mentioned here is a powerful technique in these situations. 
Development of X-ray micro beams has seen progress this decade through the use of synchrotron radiation. ${ }^{10,11)}$ The combination of our techniques with a focused x-ray source certainly creates a novel microanalysis technique. One possible application is in the field of corrosion science. We have applied the XRF and XAFS to cross sectional analysis of the rust layer formed on a weathering steel sheet. ${ }^{12)}$ In that study, only major elements, iron and chromium, were analyzed. It is well known that trace elements such as Mo improve corrosion resistance. The micro-beam XRF yield XAFS can be applied to simultaneous determination of concentration and chemical states of trace elements in rust layers with high spatial resolutions.

\section{Summary}

We have investigated the quantitativity of the XRF-yield $\mathrm{XAFS}$ for $\mathrm{Nb}$ in steel. The results show that $\mathrm{Nb}$ can be quantified with high accuracy in the wide concentration range from 2100 down to at least $31 \mathrm{ppm}$. The combination of the technique with conventional XAFS analysis provides information about quantity, chemical states, and local crystal structure from identical sample volumes. The technique can be applied to studies revealing inhomogeneous structures in steel and related materials.

\section{Acknowledgements}

This work was carried out by a fruitful collaboration with Photon Factory, KEK. The authors thank to Dr. N. Usami for her technical support. They also thank to Dr. T. Yamashita and Ms. N. Makiishi, Steel Research Laboratory, JFE Steel Corporation for sample preparation.

\section{REFERENCES}

1) Y. Funakawa, T. Shiozaki, K. Tomita, T. Yamamoto and E. Maeda: ISIJ Int., 44 (2004), 1945.

2) For example, E. Orowan: Discussion in The Symp. on Internal Stresses in Metals and Alloys, Inst. Metals, London, (1948), 451.

3) S. Pizzini, K. J. Roberts, W. J. Phythian, C. A. English and G. N. Greares: Philos. Mag. Lett., 61 (1990), 223.

4) T. Watanabe: User Experiment Report Spring-8 (2002A), No. 9 (2003), 177.

5) M. Nagoshi: User Experiment Report Spring-8 (2003A), No. 11 (2003), 12.

6) M. Nagoshi, T. Kawano, K. Sato, Y. Funakawa, T. Shiozaki and K. Kobayashi: Physica Scr., T115 (2005), 480.

7) A. C. Leri, M. B. Hay, A. Lanzirotti, W. Rao and S. C. B. Myneni: Anal. Chem., 78 (2006), 5711.

8) For example, XAFS, ed. by T. Ota, ICP Publisher, Tokyo, (2002), 59.

9) S. Kinoshiro, T. Ishida, M. Inose and K. Fujimoto: Tetsu-to-Hagané, 89 (2013), 362.

10) S. Hayakawa, N. Ikuta, M. Suzuki, M. Wakatsuki and T. Hirokawa: J. Synchr. Radiat., 8 (2001), 328.

11) S. Matsuyama, H. Miura, H. Yumoto, Y. Sano, K. Yamamura, M. Yabashi, Y. Nishino, K. Tamasaku, T. Ishikawa and K. Yamauchi: Rev. Sci. Instrum., 77 (2007), 103102.

12) M. Nagoshi, T. Kawano, I. Kage and S. Hayakawa., ISIJ Int., 51 (2011), 93 . 